\title{
Occurrence and Distribution Characteristics of Antibiotic Resistance Genes in Sediments Between Urban and Rural of the Liaohe River Basin, China
}

\section{Guangshui Na ( $\sim$ gsna@nmemc.org.cn )}

National Marine Environmental Monitoring Center, China

\section{Keyu Zhang}

Shanghai Ocean University

Hui Gao

National Marine Environmental Monitoring Center, China

Ruijing Li

National Marine Environmental Monitoring Center, China

Shuaichen Jin

National Marine Environmental Monitoring Center, China

Fuqiang Zhao

Dalian Ocean University

Haibo Zhang

National Marine Environmental Monitoring Center

Shisheng Li

Shanghai Ocean University

\section{Research Article}

Keywords: Antibiotic Resistance Genes (ARGs), Mobile Genetic Elements (MGEs), High-throughput qPCR, Sediments, tnpA , Urban and rural

Posted Date: March 1st, 2021

DOl: https://doi.org/10.21203/rs.3.rs-249715/v1

License: (c) (i) This work is licensed under a Creative Commons Attribution 4.0 International License.

Read Full License 


\section{Abstract}

Antibiotic Resistance Genes (ARGs) are considered to be emerging pollutants related to human activities. The rapid development of global urbanization has expanded human activities, thereby exacerbating the global human health risks caused by antibiotic resistance genes. The effects of urban and rural environments are multifarious, which makes the source and distribution of ARGs in the environment diversification. Understanding the distribution and spread of ARGs is essential for studying the environmental behavior of ARGs. In this study, the occurrence 296 genes were detected by the highthroughput qPCR technology, and FC value was used to analyze the diversity of ARGs and Mobile Genetic Elements (MGEs) in sediments between urban and rural areas of the Liaohe River Basin, China. The cooccurrence of MGEs and ARGs was analyzed using network to decipher core genes. A total of 187 ARGs and 10 MGEs were detected in all sediment samples. The average number of genes detected in urban sites is 89 higher than that in rural sites. The high abundance and various types of ARGs and MGEs detected in urban river sediments indicates that the occurrence of urban ARGs is more complex. MGEs were detected high levels and were significantly correlated with the abundance and diversity of ARGs in river sediments providing evidence that MGEs were related to the occurrence and distribution of ARGs and tnpA(tnpA-07, tnpA-01 and tnpA-03) gene were at the key position of co-occurrence of various types of ARGs.

\section{Introduction}

Antibiotics have antibacterial properties, prevent diseases and promote growth (Danner et al 2019), so they are widely used in the prevention and treatment of human and livestock diseases, as well as in the breeding of livestock and aquaculture animals, which caused an increase in resistance to various antibiotics, posing a major threat to modern health work (Davies et al, 2010). Studies have shown that antibiotic resistance is a natural phenomenon, and human activities accelerate the spread of ARGs (Chen et al, 2013). At the same time, a variety of abiotic factors such as antibiotics, heavy metals and organic compounds are related to the occurrence of antibiotic resistance ( $\mathrm{Li}$ et al, 2018). The appearance and distribution of ARGs in various environmental media have been found in sewage treatment plants (Rizzo et al, 2013), soil (Wang et al, 2014), sediments (Zhu et al, 2017), surface freshwater (Peng et al, 2019) and other locations. The river environment can provide an ideal environment for the physical transportation, acquisition and dissemination of ARGs, which is related to the comprehensive influence of the differences between urban and rural (Marti et al, 2014).

Antibiotics exhibit a pseudo-persistent state in the natural environment, which means antibiotics will continue to exert selective pressure on bacterial communities, increasing the possibility of spontaneous mutations and horizontal gene transfer in bacterial communities to produce emergence and spread of of ARGs (Grenni et al, 2018) among different microbial species through plasmids, phages and genome islands.In addition to the horizontal transfer of ARGs mediated by MGEs, ARGs can also promote ARGs to spread more frequently among different microbial species through plasmids, phages and genome islands. The comparative research (Nadine et al, 2015) on the functional river antibiotic resistance before 
and after adding wastewater from sewage treatment plants showed that potential way to spread ARG in rivers through sewage treatment plants, and treatment significantly increases the copy number of aminoglycoside resistance genes in downstream rivers. At present, most researches focus on the characteristics of the occurrence of antibiotic resistance genes in river waters (Wang et al, 2016; Martie et al, 2018), while ARGs in sediments are 120 to 2,000 times higher than in water samples (Luo et al, 2010) and research on sediments of urban and rural is lacking.

The Liaohe River Basin has obvious characteristics of trans-regional rivers. In the urban clusters of the Liaoning privilege section of the Liaohe River Basin, the river water is overloaded to absorb the industrial wastewater and domestic sewage of the cities along the way. According to statistics, a total of 24,748 tons of antibiotics (Zhang et al, 2015) and $9.47 \times 10^{13}$ copies/person/day of ARGs in China have been released into rivers and related waterways (Su et al, 2017). Correspondingly, incomplete urban infrastructure construction has caused a large amount of urban sewage to flow into the river, which has brought huge pressure on the local environment during the rapid urbanization and industrialization process and has a huge impact on the ecology (Pan et al, 2012), causing contamination of antibiotics resistance genes (Wu et al, 2019). Relatively, rural pollution is mainly pollution from agriculture, fertilizers, and domestic waste (Tang et al, 2008, Wang et al, 2017). Comparison of urban and rural pollutant differences can better understand the speed and direction of the pollution process in the course of urbanization.

This study adopted a high-throughput qPCR design using 296 pairs of primers in urban and rural river sediments of the Liaohe River Basin. Comparative analysis of the urban-rural distribution of ARGs in the sediments of the Liaohe River Basin and exploring the diversity and differences of antibiotic resistance genes in the sediments of the region. Combining the characteristics of the urban and rural to explain their relationship with the surrounding environment provides a better understanding of the factors that affect the dynamic changes of ARGs in different environments. 296 ARGs and MGEs and 16S rRNA were detected and compared between urban and rural areas. Using reservoirs as a reference point, it is of great significance to study the distribution of ARGs in urban and rural river sediments, and to establish the relationship between ARGs pollution and urban and rural areas. The relationship between MGEs and ARGs was also explored. Understanding the core genes in the urban sediment environment is essential for formulating effective strategies to alleviate antibiotic resistance. The results of this work provide valuable data for evaluating the current status of ARGs in the study area and contribute to a better understanding of future ARGs pollution in urban and rural areas.

\section{Materials And Methods}

\section{Sample collection and physicochemical property determination}

In June 2019, the sediment sampling stations are set up in Figure 1: D1, H4, and T5 sampling stations are located in the city, and the surrounding population is densely populated. There are many hospitals nearby, and the river is more susceptible to human influence. $\mathrm{H} 1, \mathrm{~L} 4$, and $\mathrm{L} 7$ are located in rural or mountainous 
areas with relatively small populations, and human factors have little influence. $\mathrm{H6}$, which is located at the reservoir point, was selected as the contrast point. Compared with the normal river environment, the reservoir environment may be less susceptible to the pollution of antibiotics and ARGs (Su et al, 2014), and most reservoir systems were located in some relatively primitive areas, with almost no human activities except for river input. The area were an important source of drinking water, which reflects the original pollution state of the river. At each sampling point, a sediment sampler was used to collect sediment samples within $2 \mathrm{~cm}$ of the mud-water interface. The sediment samples are collected and placed in aseptic bags and stored in an ice box $\left(4^{\circ} \mathrm{C}\right)$, and taken back to the laboratory within 24 hours for storage. Stored in a refrigerator at $-20^{\circ} \mathrm{C}$ for later use. The standard method (GB18668-2002) was used to determine the total organic carbon (TOC) content in the sediment in the laboratory.

\section{DNA extraction and High-throughput quantitative PCR}

The PowerSoil DNA Isolation Kit (MOBIO, CA) was used to extract DNA from the sediment with a $0.25 \mathrm{~g}$ sample according to the instructions of the kit. The concentration and purity of DNA were measured and evaluated on Nano-Drop spectrophotometer(Nano-drop Technologies Inc. Wilmington, DE). The absorbance value of DNA A260/A280 was 1.8 to 2.0 , and the extracted DNA stored at $-20^{\circ} \mathrm{C}$ for subsequent analysis.

The Wafergen smart chip real-time PCR system was used for high-throughput qPCR reactions. The system could be used for large-scale gene expression studies, and could process 5184 nanocell responses per run (Wang et al, 2014). All primers used in this study are shown in Table 1.A total of 296 primer sets were used, including 295 primer sets, targeting almost all major categories of ARGs and mobile genetic elements (MGEs) and a 16S rRNA gene. ARGs are divided into 9 categories of antibiotic resistance genes (such as aminoglycosides, $\beta$-lactams, chloramphenicols, Macrolide-LincosamideStreptograminB (MLSB) resistance genes, multidrugs, sulfonamides, Tetracyclines, vancomycins and others) and MGEs. These ARGs represent almost all major classes of antibiotics widely used in humans and animals. The PCR reaction mixture was first added to the microwell chip using the (296assays) $\times 16$ (samples) mode of the MSND (MSND), and then the GPCR reaction was performed on the cycler. Reaction system: $1 \times$ LightCycler 480 SYBR Gree I Master, $500 \mathrm{nM}$ each primer, DNA template $2 \mathrm{ng} / \mathrm{uL}$, total reaction volume: $100 \mathrm{~nL}$.

After the initial enzyme was activated at $95^{\circ} \mathrm{C}$ for $10 \mathrm{~min}$, amplification was carried out using 40 cycles of the following procedure: denaturation at $95^{\circ} \mathrm{C}$ for 30 seconds, and annealing at $60^{\circ} \mathrm{C}$ for 30 seconds. The melting process is automatically generated by the Wafergen software. SmartChip qPCR software was used to analyze the results, multiple peaks or wells whose amplification efficiency exceeded the range (90\%-110\%) were excluded and then screened for (1) A threshold cycle (CT) must be $\leq 31$, (2) Positive samples must be repeated three times simultaneously. Calculate the relative copy number (Eq.1) was calculated based on previous studies (Chen et al, 2018). In addition, the method of comparing CT was 
also used to calculate the FC value of ARGs between the modified sample and the control (Eq. 2) (Schmittgen et al, 2008).

$$
\begin{aligned}
& \text { Gene copy number }=10^{\left(31-C_{T}\right) /(10 / 3)} \\
& \Delta C_{T}=C_{T(A R G)}-C_{T(16 S)} \\
& \Delta \Delta C_{T}=C_{T(\text { Target })}-\Delta C_{T(\text { Ref })} \\
& \mathrm{FC}=2^{\left(-\Delta \Delta C_{T}\right)}
\end{aligned}
$$

CT is the threshold cycle, and the detection limit CT (31) is used to replace the non-amplified gene. ARG is one of 295 genes, $16 \mathrm{~S}$ is the 16S rRNA gene, Target is the treatment group sample, and Ref is the control sample (Chen et al, 2016).

\section{Absolute quantification of 16S rRNA}

Amplification with Roche was carried out as follows: The qPCR reaction $(20 \mu \mathrm{L})$ consists of $10 \mu \mathrm{L}$ $2 \times$ LightCycler 480 SYBR ${ }^{\circledR}$ Green I Master Mix, $1 \mu \mathrm{M}$ per primer (the same primers used in high-throughput qPCR), $1 \mu \mathrm{L}$ DNA template, and $7 \mu \mathrm{L}$ nucleic acid-free water. Amplify with Roche 480 as follows: Initially preheat at $95^{\circ} \mathrm{C}$ for 5 minutes, then perform 40 cycles at $95^{\circ} \mathrm{C}$ for $15 \mathrm{~s}, 60^{\circ} \mathrm{C}$ for 1 minute, and $72{ }^{\circ} \mathrm{C}$ for $15 \mathrm{~s}$ to contain 16S rRNA for clonal sequencing. The standard plasmid of the gene fragment $\left(1.39 \times 10^{10}\right.$ copies/L-1) was used as the 8-point calibration curve of its 10 -fold dilution for the calculation of the external standard $(r=0.96, P<0.01)$. Therefore, the relative copy number of ARGs generated by highthroughput qPCR can be converted to absolute copy number by normalizing to absolute 16S rRNA gene copy numbers.

\section{Data analysis}

SmartChip qPCR software (V2.7.0.1) was used to analyze the results of high-throughput qPCR, and discard multiple peaks and amplification efficiency beyond the range. The threshold period (CT) 31 is the detection limit. Samples with only three replicates were considered positive, the correlation analysis was conducted using Pearson's correlation coefficient, Wilcoxon signed-rank test was used for the diversity analysis and network construction. Data processing and charts were made with Excel 2016 and R Studio related software packages, TBtools (Chen et al, 2020) was used to make heat maps, and Gephi 0.9.2 was used to make co-occurrence network(Pearson, $p<0.05$, Closeness Centrality, $|\rho| \geq 0.6$ ) structure diagrams.

\section{Results And Discussion}

\section{Diversity of ARGs and MGEs}


A total of 187 genes were detected in all samples, including 177 ARGs, 10 mobile genetic element (MGEs) genes (including 8 transposon genes and 2 integron genes) and 16S rRNA genes. The detected ARGs almost included all major types of antibiotic resistance genes (aminoglycosides, beta-lactams, chloramphenicols(Chlor), Macrolide-Lincosamide-StreptograminB (MLSB) resistance genes, multidrugs, sulfonamides(Sul), tetracyclines(Tet), vancomycin(Van) and others(Figure 2) and the three main resistance mechanisms including antibiotic inactivation, efflux pump, and cell protection, as well as other mechanisms, transposon and integron genes (Figure 3). In general, the average number of genes detected in urban sites is 89 higher than that in rural sites. 104 ARGs were detected at the urban site $\mathrm{H} 4$ with the most and 70 at the rural site L7 were the least. The number of genes detected is not significantly different between urban and rural areas $(P=0.109>0.05)$, which indicated that the rural river sediments in the region may be affected by river flow, leading to insignificant differences between the urban and rural areas. The sediments in the Liaohe River Basin were influenced by a variety of ARGs, which is not only reflected in the diversity of the types of ARGs detected in the sediments, but also affected by ARGs with different resistance mechanisms. Drug-resistant bacteria against sulfonamides, tetracycline, chloramphenicol, quinolones and other antibiotics usually carry one or more resistance mechanisms ARGs, including cell protection mechanism genes such as sul2, tetM, tet $T$, etc. Drug efflux pump mechanism genes $f l o R$, tetH, $\operatorname{ttg} B$, etc. The drug-resistant genes cata 1 , aadA1, and $\operatorname{str} B$ with inactivated drug active sites have been qualitatively detected in humans, livestock and poultry and isolates from multiple environmental media (McKinney et al, 2010). Antibiotic inactivation is the main resistance mechanism, and the total abundance of antibiotic inactivation $6.02 * 10^{9} \mathrm{copies} / \mathrm{g}$ accounts for more than half of the detection of total resistance mechanism, which was similar to the detection result of Jiulongjiang (Ouyang, 2014). Compared with other resistance mechanisms, antibiotic inactivation mechanism genes are more conducive to the survival of resistant bacteria under the condition of antibiotic residues in the environment.

Through correlation analysis, it was found that there was no significant difference between the types of resistance genes and the number of resistance mechanisms detected in urban and rural areas $(P=0.102>0.05)$ (Figure 2, Figure3). This may be due to the impact of the exchange effect caused by the river flow. However, based on the results of the cluster analysis of the points, there are differences in the average number and distance between the types of resistance genes and the number of resistance mechanisms detected in urban and rural areas. Compared with rural areas, ARGs induced by urbanization contain more types and mechanisms of drug resistance genes, and the corresponding effects of human factors such as urban hospital discharge and sewage discharge during urban treatment can not be ignored. So that, the number of types and mechanisms detected in urban areas (total 267) is higher than that of detection mechanisms than that checked out in the village (total 245) (Figure 3).

\section{Abundance of ARGs and MGEs}

\section{Absolute abundance of ARGs and MGEs}


The total abundance of the major types of ARGs and MGEs was $10^{6} \mathrm{copies} / \mathrm{g} 10^{9} \mathrm{copies} / \mathrm{g}$ (Figure 4), aminoglycoside resistance gene (Aminoglycoside) $4.39 * 10^{9}$ copies/g and multidrug resistance gene (Multidrug) $3.57 * 10^{9}$ copies/g have the highest total abundance detected. Chloramphenicol (Chlor) and Vancomycin (Van) were the lowest detected, respectively $3.67 * 10^{7} \mathrm{copies} / \mathrm{g}$ and $2.85^{\star} 10^{7} \mathrm{copies} / \mathrm{g}$. The total abundance detected by MGEs was $1.76 * 10^{9} \mathrm{copies} / \mathrm{g}$, indicating that the horizontal gene transfer (Horizontal Gene Transfer, HGT) possibility of ARGs in the sample is higher. This is congruent with a previous report, which suggested that the abundance and diversity of integrons were correlated with the abundance and diversity of ARGs(Chen et al, 2013).

Among all the detected genes, genes such as sul2, qacEdelta 1-01 and aadA-02 were highly detected in urban and rural areas; genes such as vanHB, blaSHV-01 and tetB-02 were relatively low in urban and rural areas (Figure 5). The highest gene is qacEdelta 1-01 with an abundance of $1.50 * 10^{9} \mathrm{copies} / \mathrm{g}$. The number of total genes detected was the highest at point $\mathrm{H} 4$, and the detected abundance was $8.72 * 10^{9}$ copies/g, followed by T5, and L4 was the lowest (Figure 6). Since the level of ARGs is closely related to the degree of human influence, human activities have a high degree of impact on urban rivers. Czekalski studied the distribution characteristics of ARGs in the Vidi Bay of Lake Geneva and found that ARGs showed a trend of gradually decreasing from the center of the pollution source to the distance (Czekalski, 2014), while H4 is located in Shenyang city with dense population and numerous hospitals. It was speculated that the higher detection of ARGs at $\mathrm{H} 4$ was closely related to human activities. Lu studied the pollution status and fate of sulfa resistance genes in the Daliao River estuary and Liao River estuary, and the results also showed that changes in factors affecting the transmission ability of ARGs in the estuary area may lead to changes in the occurrence status of ARGs (Lu et al, 2015). D1 is located at the estuary of the Daliao River. Due to the interaction between seawater and river water, the detection of ARGs at D1 in cities was lower than that at L7 in rural areas. The lower ARGs detection at point D1 in the estuary area may be reflected to the combined effect of the ocean and rivers in the estuary area, while the human factors may be relatively weak.

Through comparative analysis of the absolute abundance of ARGs detected in urban and rural sites, it was found that there was significant difference between urban and rural $(P=0.039<0.05)$, and the abundance level appears to be higher in cities than in rural (Figure 7). Except for vancomycin-type Van ARGs, the detection rates in urban were higher than those in rural. The ARGs detected in cities have the characteristics of high abundance, strong diversity, and diverse structures. The concentration of antibiotics in the rivers is detected at sub-inhibitory levels to produce the flora in the river environment certain pressure selection (Henando et al, 2006, Graham et al, 2010). The selection of antibiotic-resistant bacteria at low antibiotic concentrations is carried out in the presence of other environmental factors such as heavy metals and pesticides (Gullberg et al, 2011). The above conditions may cause the detection of ARGs in urban river sections to show the above characteristics. The increase in the abundance and number of ARGs in urban rivers may be influenced by the selective pressure exerted by antibiotics or other chemicals released by human and veterinary applications( $\mathrm{Li}$ et al, 2020). 


\section{FC value of ARGs and MGEs}

The FC value represents the fold relationship between the detected gene and the control group. The same control is used to analyze the relative fold relationship between the study samples under different treatments or influencing factors. When the water passes through the water purification facilities of the reservoir, common pollutants, antibiotics and ARGs in the reservoir flowing from the river are removed, and the reservoir system effectively controls antibiotics and antibiotic resistance to acceptable levels ( $\mathrm{Li}$ et al, 2020). Therefore, the $\mathrm{H} 6$ point of the upstream reservoir was selected as a reference to calculate the FC value of the detected ARGs and MGEs. Of the 177 ARGs and 10 MGEs detected, 55 (29.4\%)were detected in urban and rural areas and controls (Figure 8), while there were 20(10.7\%), 23(12.3\%), and $21(11.2 \%)$ uniquely detected genes in urban, rural, and control sites, respectively. Compared with the number of common detections between the control group and the urban and rural areas, the common detection categories of the urban and rural areas overlap more, indicating that the environment after the reservoir treatment in the control group is different from the environment in the normal urban and rural river system. Factors such as river flow and human activities will also affect the occurrence of ARGs in river sediments. For the reservoir control, 21(11.2\%) unique genes were detected, which may be caused by the decrease of water flow velocity in the ecological water storage area of the reservoir. The precipitation of suspended solids and organic matter in the pretreatment zone, and the combined influence of aquatic plants and microorganisms (Fang et al. 2017), indicating that the ARGs of the reservoir are affected by the combined effects of natural environmental factors and anthropogenic factor. The observation of 55 (29.4\%) ARGs in the reservoir showed that they were resistant to all major antibiotics, and were enriched in rural and urban areas. This supports the existing findings that the background of drug resistance is widespread in the natural environment (D 'Costa et al. 2011).

According to the distribution map of FC value of each category (Figure 9), it can be seen that the genes detected in sediments in urban and rural were generally higher than those in sediments in reservoirs. Aminoglycoside resistance gene was detected in urban and rural areas with a relatively high multiple of FC value range from 607.57 to 7176.08 . It has showed that 83 genes (Figure 2) were detected at point D1 and the FC value at this point was 1.49 607.57, further indicating that ARGs pollution in the estuary area was influenced by different factors than urban and rural and control reservoirs. The FC heat map (Figure 10) shows that the urban (outer circle) is more enriched than the rural (inner circle). Further analysis of the ARGs profile in the control reservoir and urban and rural sediments, the ARGs in the urban sediments may be composed of two types of natural origin and exogenous sources ( $\mathrm{Li}$ et al, 2020).

\section{Analysis of ARGs Influencing Factors}

The sum of the concentration of each type of ARGs is the total ARGs of this type of ARGs. The correlation between each type of total ARGs and 16S rRNA, TOC and MGEs was analyzed: Except for Vancomycin (Van) of 9 types of ARGs, the other types were positively correlated with MGEs $(P<0.01$ or $P<0.05)$, indicating that MGEs play an important role in the transfer and spread of ARGs(Table 1). The absolute abundance of ARGs was related to 16S rRNA. 16S rRNA represents to a certain extent the level of 
biomass in the sediments of the study sites. The increase or decrease of biomass may be another way to regulate ARGs (Huang et al, 2015). The low difference in biomass levels in urban and rural sediments in this study may be a reason for the insignificant difference in ARGs. MGEs can be used as the typical molecular characteristics of ARGs; which can try to track antibiotic-resistant pollution in rivers to identify the typical molecular characteristics of ARGs (Storteboom et al, 2010). Through the correlation diagram between sampling points and resistance gene MGEs (Figure 11), it can be seen that the H4, T5, and D1 points are highly correlated with ARGs and MGEs, which means the detected concentrations of ARGs and MGEs in urban were relatively higher than those in rural.

Table 1: Correlation between various types of ARGs and 16S rRNA, TOC and MGEs

\begin{tabular}{|llll|}
\hline & $16 S$ rRNA & MGEs & TOC \\
\hline Aminoglycoside & $0.972 \star \star$ & $0.999^{\star \star}$ & -0.299 \\
\hline Beta_Lactamase & $0.977^{\star \star}$ & $0.997 \star \star$ & -0.324 \\
\hline Chlor & $0.978^{\star \star}$ & $0.998^{\star \star}$ & -0.32 \\
\hline MLSB & $0.979 \star \star$ & $0.995^{\star \star}$ & -0.333 \\
\hline Multidrug & 0.789 & $0.891^{\star}$ & -0.397 \\
\hline Others & $0.976 \star \star$ & $0.997 \star \star$ & -0.312 \\
\hline Sul & 0.79 & $0.887 *$ & -0.312 \\
Van & 0.395 & 0.433 & -0.409 \\
\hline Tet & $0.979 \star \star$ & $0.995^{\star \star}$ & -0.333 \\
\hline
\end{tabular}

*Indicates a significant correlation $\mathrm{P}<0.05$

** indicates a very significant correlation $\mathrm{P}<0.01$

Constructing a network structure diagram of the co-occurrence of various ARGs and MGEs (Figure 12) shows that the tnpA gene in MGEs plays an important role in the co-occurrence of ARGs. TnpA is a member of the serine recombinase (SR) gene family. It has reported that the full-length TnpA proteins of IS607, IS1535 and ISC1926 bind to the DNA at the ends of their respective transposons, and chemically active TnpA oligomers play a role. The tnpA gene was at the key position of co-occurrence of various types of ARGs. The transfer of ARGs in this region is closely related to tnpA (Chen et al, 2018b). It also found that tnpA-related genes played a key role in the network structure diagram, which showed that tnpA-07 and tnpA-01 were detected at each site. TnpA-01 and tnpA-03 mainly played key node roles in the co-occurrence network of aminoglycosides, sulfonamides, $\beta$-lactams and multidrug resistance genes. In short, tnpA-07 plays a key role in the co-occurrence network of macrolides and chloramphenicol resistance genes, and the connection point of the two large modules is tnpA-03. Previous studies have shown that MGEs, as the main promotion unit of horizontal transfer, play an important role in the 
occurrence and spread of ARGs (Chen et al, 2018, Zheng et al, 2018). In summary, the occurrence and spread of ARGs in sediments is highly correlated with MGEs, especially the tnpA gene plays a key role in the co-occurrence of ARGs. The biomass characterized by $16 \mathrm{~S}$ rRNA also plays a certain role in ARGs, such as microbial community differences play a key role in the distribution of ARGs (Xiang et al., 2018). Biomass differences in urban and rural sediments, river flow, environmental factors caused by human factors, and environmental factors such as ocean and river exchange under natural conditions have an impact on the occurrence and spread of sediment ARGs.

\section{Conclusions}

In summary, this study analyzed the distribution and enrichment of 177 antibiotic resistance genes, 16SrRNA, MGEs and the distribution of resistance mechanisms detected in the sediments of the Liaohe River Basin. It shows that Antibiotic resistance gene pollution is widespread in the sediments of the Liaohe River Basin. Through the comparative analysis of urban and rural, it was found that there was significant difference in the detection between urban and rural $(P<0.05)$ and the urban resistance gene pollution is higher than that in the rural areas. MGEs play an important role in the occurrence of ARGs and tnpA-07, tnpA-01 and tnpA-03 mainly played key node roles in the co-occurrence network, which indicates that tnpA was important to the co-occurrence of ARGs. ARGs in urban and rural may be related to many factors, such as differences in pollution between urban and rural areas, differences in human activities, differences in the original existence of urban and rural natural environments, and river geographic locations such as estuaries etc.

\section{Declarations}

\section{Authors Contributions}

GSN: Conceptualization, Methodology, Supervision, Funding Acquisition; KYZ: Conceptualization, Methodology, Investigation, Visualization, Data Curation, Formal Analysis, Writing - Original Draft, Writing - Review \& Editing; HG: Methodology, Investigation, Validation, Resources, Writing - Review \& Editing; RJL: Investigation, Software, Resources; SCJ: Investigation, Software, Resources; FQZ: Visualization, Investigation, Resources; HBZ: Validation, Software, Resources; SSL: Investigation, Resources

\section{Funding}

The research was supported by the National Key Research and Development Program of China (2019YFD0901104), National Natural Science Foundation of China (41976222, 42006195, 41406088), Open Fund of State Key Laboratory of Environmental Chemistry and Ecotoxicology (KF2018-05), Open Fund for the Key Laboratory of Global Change and Marine Atmospheric Chemistry (GCMAC 1812). The Project is sponsored by “Liaoning BaiQianWan Talents Program"(201704). 
Competing interests The authors declare that they have no competing interests.

\section{Availability of data and materials Not applicable}

Consent to publish All the authors have agreed for authorship, read and approved the manuscript, and given consent for submission and subsequent publication of the manuscript.

\section{References}

Chen B, Yang Y, Liang X et al (2013) Metagenomic profiles of antibiotic resistance genes (ARGs) between human impacted estuary and deep ocean sediments. Environ. Sci. Technol. 47: 12753-12760. https://doi.org/ 10.1021/es403818e

Chen CJ, Hao C, Yi Z et al (2020) TBtools: An Integrative Toolkit Developed for Interactive Analyses of Big Biological Data. Molecular Plant, 8, 3(13): 1194-1202. https://doi.org/10.1016/j.molp.2020.06.009

Chen Q, An X, Li H et al (2016) Long-term field application of sewage sludge increases the abundance of antibiotic resistance genes in soil. Environment international, 92: 1-10.

https://doi.org/10.1016/j.envint.2016.03.026

Chen WY, Sridhar M, Stephen PH et al (2018) Multiple serine transposase dimers assemble the transposon-end synaptic complex during IS607-family transposition. Elife 7:e39611. https://doi.org/10.7554/eLife.39611

Czekalski N (2014) Wastewater as a point source of antibiotic-resistance genes in the sediment of a freshwater lake. ISME (8), 1381-1390. https://doi.org/10.1038/ismej.2014.8

Danner MC, Robertson, Behrends V et al (2019) Antibiotic pollution in surface fresh waters: Occurrence and effects. Sci. Total Environ. 664: 793-804. https://doi.org/10.1016/j.scitotenv.2019.01.406

Davies J, Davies D, (2010) Origins and evolution of antibiotic resistance. Microbiol Mol Biol Rev 74: 41733. https://doi.org/10.1128/mmbr.00016-10

D'Costa VM, King CE, Kalan L et.al (2011) Antibiotic resistance is ancient. Nature 477(7365):457-461. https://doi.org/10.1038/nature10388

Fang H, Zhang Q, Nie X et al (2017) Occurrence and elimination of antibiotic resistance genes in a longterm operation integrated surface flow constructed wetland. Chemosphere 173: 99106.https://doi.org/10.1016/j.chemosphere.2017.01.027

Graham D W, Olivares-Rieumont S, Knapp CW, et al (2010) Antibiotic resistance gene abundances associated with waste discharges to the Almendares River near Havana, Cuba. Environmental science \& technology, 45(2):418-424. https://doi.org/10.1021/es102473z 
Grenni, P, Ancona V, Barra Caracciolo A (2018) Ecological effects of antibiotics on natural ecosystems: A review .Microchemical Journal, 136: 25-39. https://doi.org/10.1016/j.microc.2017.02.006

Gullberg E, Cao S, Berg OG, et al (2011) Selection of resistant bacteria at very low antibiotic concentrations. Plos Pathog 7(7). https://doi.org/10.1371/journal.ppat.1002158

Henando MD, Mewua M, Femindea AAR et al (2006) Environmental risk assessment of pharmaceutical residues in wastewater effluents, surface waters and sediments. Talanta, 69(2):334-3424. https://doi.org/10.1016/j.talanta.2005.09.037

Huang X, Liu C, Li K et al (2015) Performance of vertical up-flow constructed wetlands on swine wastewater containing tetracyclianes and tet genes. Water Res. 70: 109-117. https://doi.org/10.1016/j.watres.2014.11.048

Li P, Wu YF, He YL et al (2020) Occurrence and fate of antibiotic residues and antibiotic resistance genes in a reservoir with ecological purification facilities for drinking water sources. Science of the Total Environment 707:135-276. https://doi.org/10.1016/j.scitotenv.2019.135276

Li Q, Na G, Zhang L, Lu Z et al (2018) Effects of corresponding and non-corresponding contaminants on the fate of sulfonamide and quinolone resistance genes in the Laizhou Bay, China. Mar. Pollut. Bull. 128: 475-482. https://doi.org/10.1016/j.marpolbul.2018.01.051

Luo Y, Mao D, Rysz M, et al (2010) Trends in antibiotic resistance genes occurrence in the Haihe River, China. Environmental science \& technology, 44(19): 7220-7225. https://doi.org/10.1021/es100233w

Lu ZH, Na GS, Hui G et al (2015) Fate of sulfonamide resistance genes in estuary environment and effect of anthropogenic activities. Science of the Total Environment, 429-438. https://doi.org/10.1016/j.scitotenv.2015.04.101

Marti EV, Ariatza E, Balcazar JL (2014) The role of aquatic ecosystems as reservoirs of antibiotic resistance. Trends Microbiol, 22(1): 36-41. https://doi.org/10.1016/j.tim.2013.11.001

Martie H, Rodriguezmozaz S (2018) Abundance of antibiotic resistance genes and bacterial community composition in wild freshwater fish species. Chemosphere, 196: 115-119.

https://doi.org/10.1016/j.chemosphere.2017.12.108

McKinney CW, Loftin KA, Meyer MT et al (2010) Tet and Sul antibiotic resistance genes in livestock lagoons of various operation type, configuration, and antibiotic occurrence. Environmental Science \& Technology, 16(44): 6102-9. https://doi.org/10.1021/es9038165

Nadine Czekalski, Radhika Sigdel ,Julia,Birtel (2015) Does human activity impact the natural antibiotic resistance background? Abundance of antibiotic resistance genes in 21 Swiss lakes. Environment International 81, 45-55 https://doi.org/10.1016/j.envint.2015.04.005 
Ouyang WY, Huang FY, Zhao Y et al (2014) Increased levels of antibiotic resistance in urban stream of Jiulongjiang River, China Appl Microbiol Biotechnol, 99(13):5697-707. https://doi.org/10.1007/s00253015-6416-5

Pan, K., Wang, W., (2012) Trace metal contamination in estuarine and coastal environments in China. Science of The Total Environment. 421 3-16. https://doi.org/10.1016/j.scitotenv.2011.03.013

Peng F, Isabwe A, Guo Y et al (2019) An extensively shared antibiotic resistome among four seasons suggests management prioritization in a subtropical riverine ecosystem. Sci. Total Environ. 673, 533540.https://doi.org/10.1016/j.scitotenv.2019.04.031

Qing L, Chen X, LiAna B et al (2018a) Long-term organic fertilization increased antibiotic resistome in phyllosphere of maize. Science of the Total Environment 645: 1230-1237. https://doi.org/ 10.1016/j.scitotenv.2018.07.260

Rizzo L, Manaia C, Merlin C, Schwartz, T, Dagot C et al (2013) Urban wastewater treatment plants as hotspots for antibiotic resistant bacteria and genes spread into the environment: A review. Sci. Total Environ. 447: 345-360. https://doi.org/ 10.1016/j.scitotenv.2013.01.032

Schmittgen T D, Livak K J (2008) Analyzing real-time PCR data by the comparative CT method. Nature protocols, 3(6): 1101. https://doi.org/10.1038/nprot.2008.73

Storteboom H, Arabi M, Davis JG et al (2010) Identification of antibiotic-resistance-gene molecular signatures suitable as tracers of pristine river, urban, and agricultural sources. Environ Sci Technol 44(6):1947-1953. https://doi.org/10.1021/es902893f

Su HC, Pan CG, Ying GG (2014) Contamination profiles of antibiotic resistance genes in the sediments at a catchment scale. Science of The Total Environment, 490: 708-714.

https://doi.org/10.1016/j.scitotenv.2014.05.060

Su JQ, An XL, Li B et al (2017) Metagenomics of urban sewage identifies an extensively shared antibiotic resistome in China. Microbiome, 5(1): 84. https://doi.org/10.1186/s40168-017-0298-y

Tang LX, Ting Z (2008) Investigation and Analysis of China's Rural Pollution Situation-Data from 141 villages across the country. China Rural Observation (01):3138区

Xiang Q, Chen Q, Zhu D et al (2018) Spatial and temporal distribution of antibiotic resistomes in a periurban area is associated significantly with anthropogenic activities. Environ. Pollution. 235: 525-533. https://doi.org/10.1016/j.envpol.2017.12.119

Wang F, Qiao M, Su J, Chen Z et al (2014) High throughput profiling of antibiotic resistance genes in urban park soils with reclaimed water irrigation. Environ. Sci. Technol. 48: 9079-9085. https://doi.org/10.1021/es502615e 
Wang M, Shen W, Yan L et al (2017) Stepwise impact of urban wastewater treatment on the bacterial community structure, antibiotic contents, and prevalence of antimicrobial resistance. Environ. Pollut. 231,1578-1585. https://doi.org/10.1016/j.envpol.2017.09.055

Wang N, Guo X Y, Yan Z et al (2016) A Comprehensive Analysis on Spread and Distribution Characteristic of Antibiotic Resistance Genes in Livestock Farms of Southeastern China. PLoS ONE (7): e0156889.https://doi.org/10.1371/journal.pone.0156889

Wu D, Su Y L, Xi H, et al (2019) Urban and agriculturally influenced water contribute differently to the spread of antibiotic resistance genes in a mega-city river network. Water Research, 158:1121. https://doi.org/10.1016/j.watres.2019.03.010

Zhang QQ, Ying GG, Pan CG et al (2015) Comprehensive evaluation of antibiotics emission and fate in the river basins of China: source analysis, multimedia modeling, and linkage to bacterial resistance. Environ Sci Technol, 49(11): 6772-6782. https://doi.org/10.1021/acs.est.5b00729

Zheng J, Zhou Z, Wei Y et al (2018) High-throughput profiling of seasonal variations of antibiotic resistance gene transport in a peri-urban river. Environ. Int. 114: 87-94. https://doi.org/10.1016/j.envint.2018.02.039

Zhu Y, Zhao Y, Li, B et al (2017) Continental-scale pollution of estuaries with antibiotic resistance genes. Nat. Microbiol. 2: 1-7.https://doi.org/10.1038/nmicrobiol.2016.270

\section{Figures}




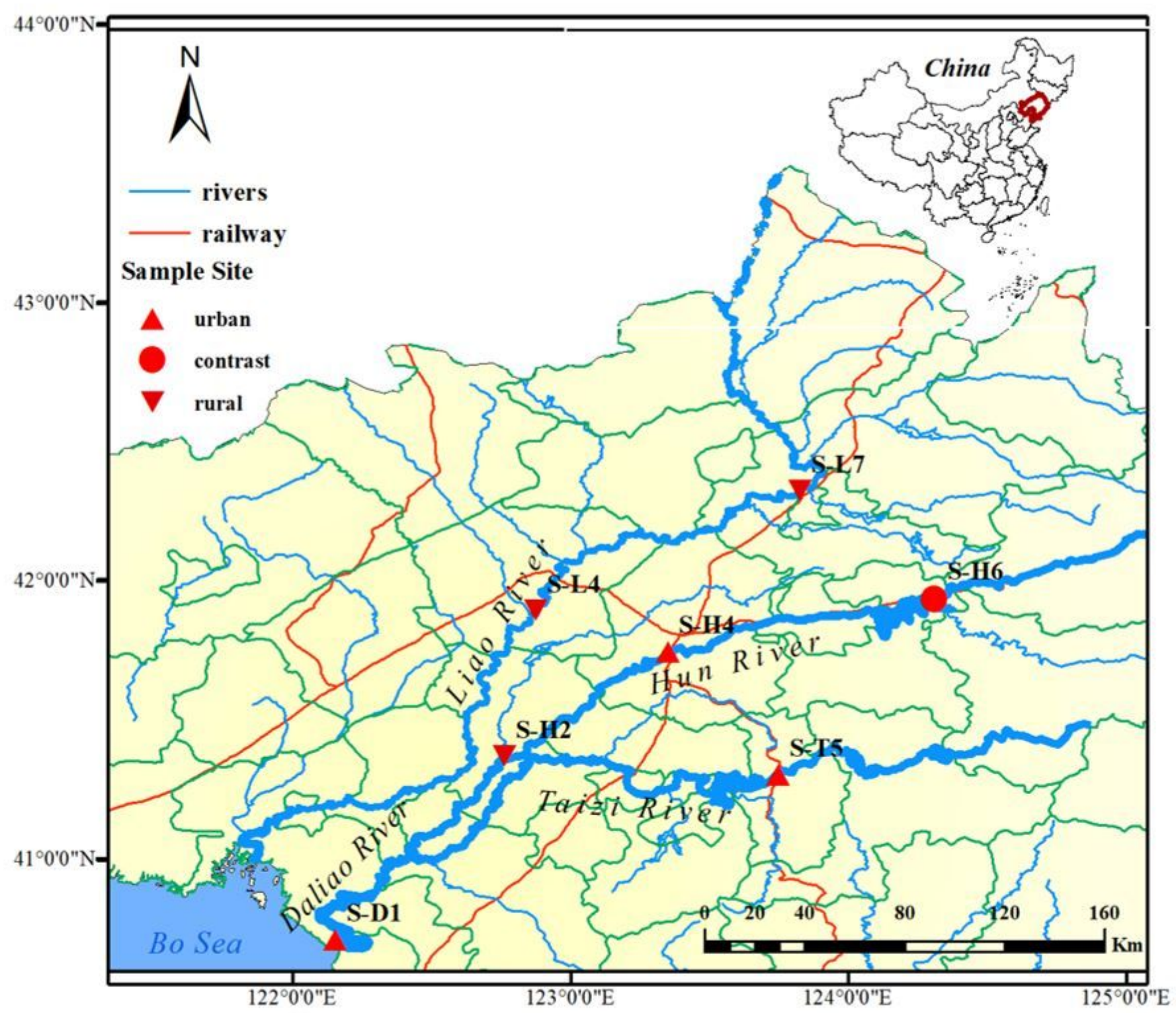

\section{Figure 1}

Sampling stations. Note: The designations employed and the presentation of the material on this map do not imply the expression of any opinion whatsoever on the part of Research Square concerning the legal status of any country, territory, city or area or of its authorities, or concerning the delimitation of its frontiers or boundaries. This map has been provided by the authors. 


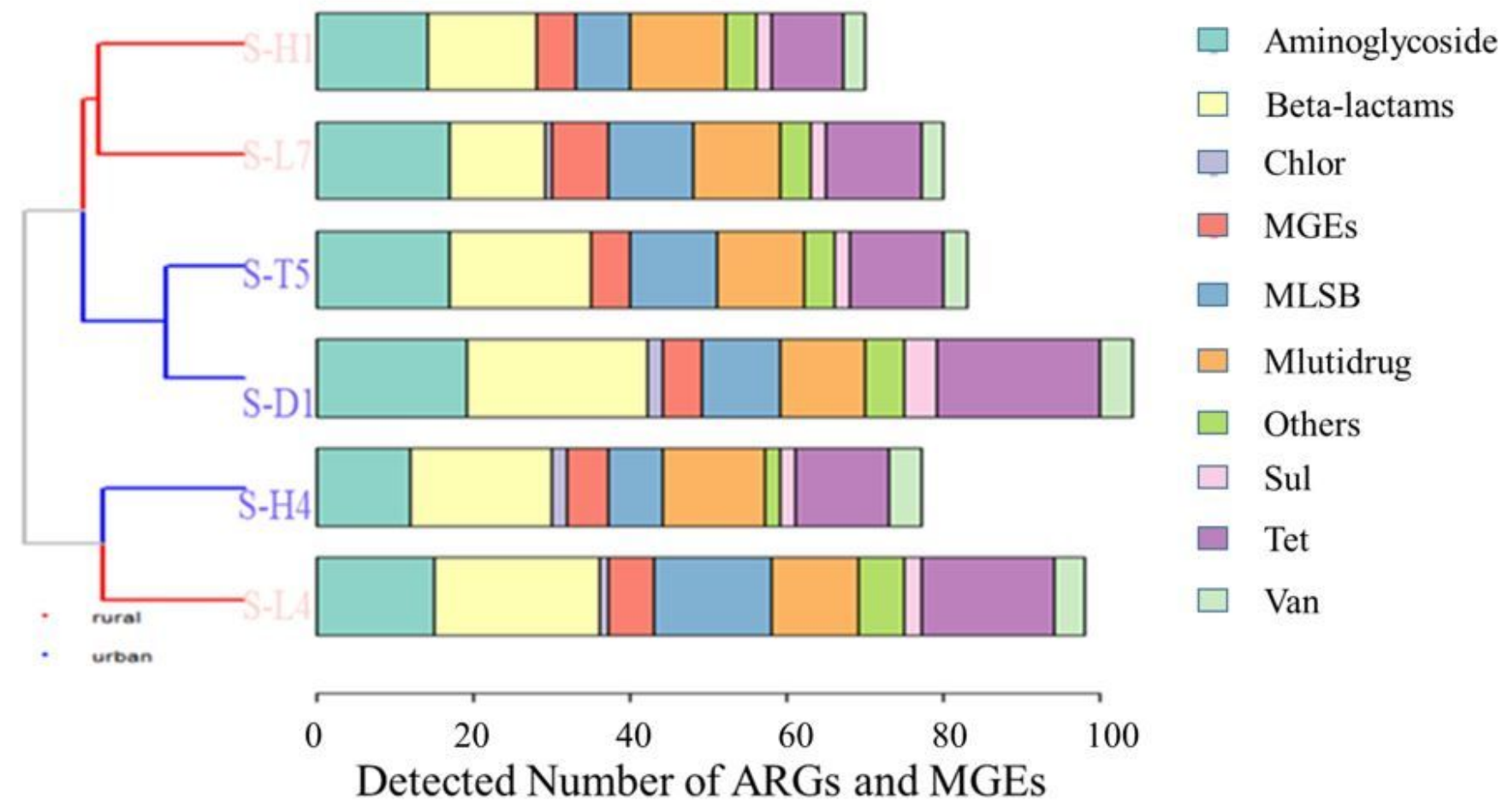

Figure 2

The number of ARGs and MGEs detected in each category

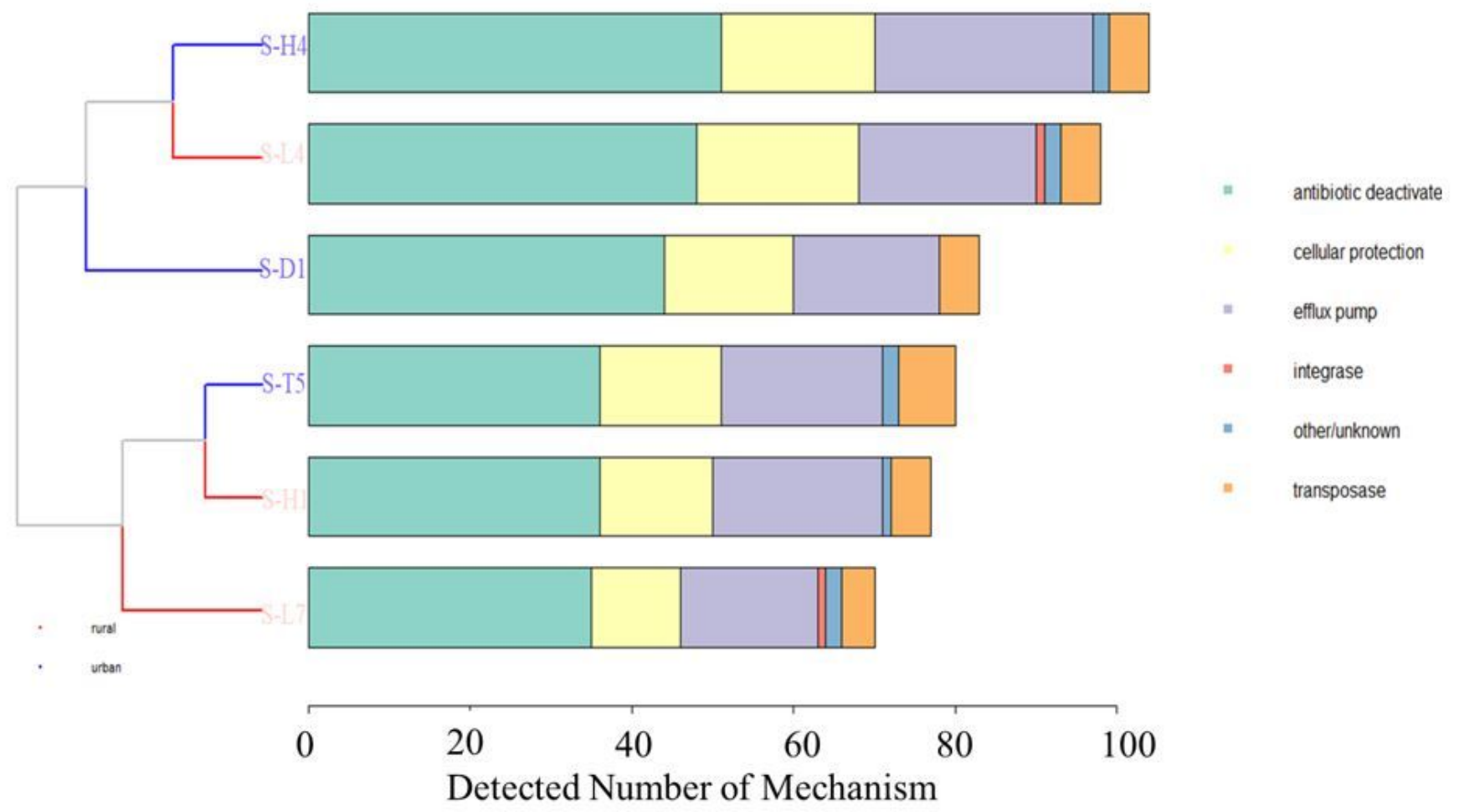

Figure 3 
The number of detected resistance mechanisms in each category

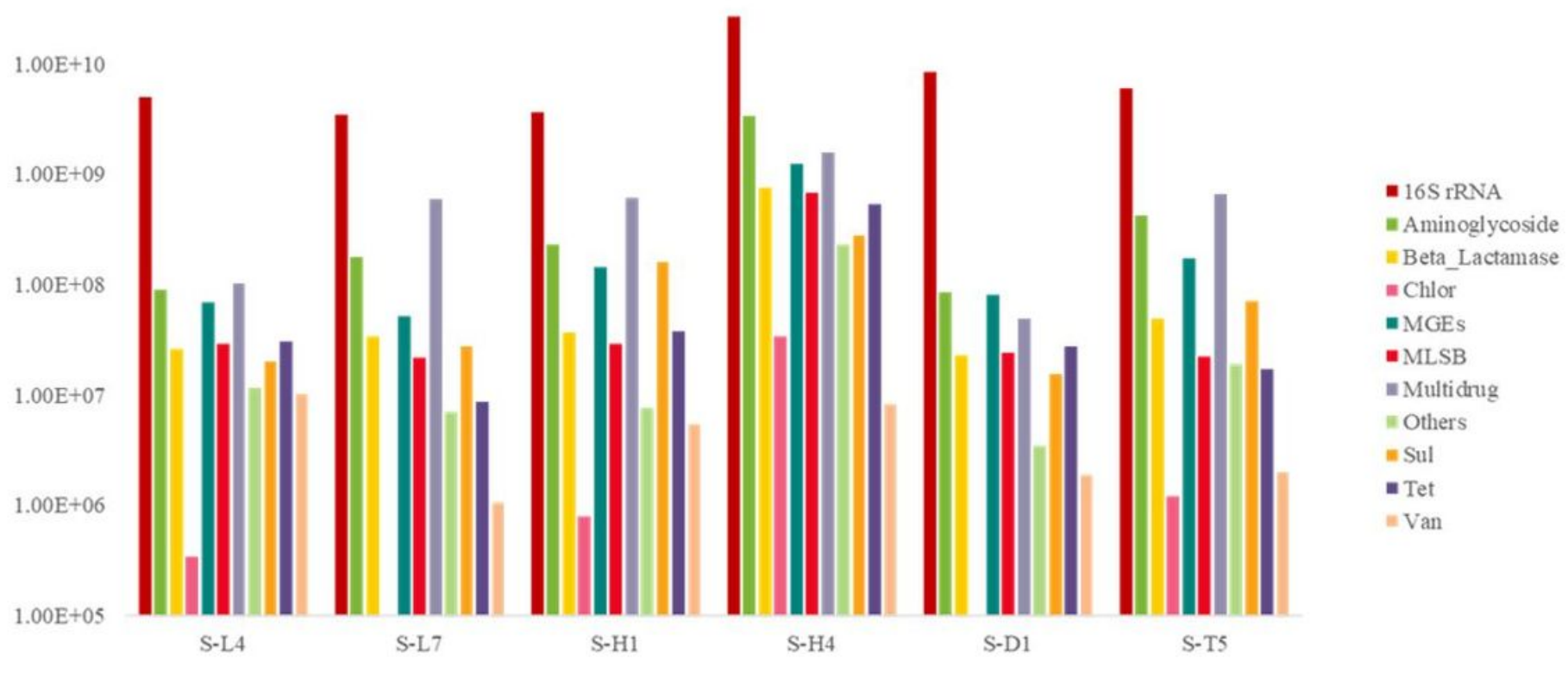

Figure 4

Total absolute abundance of ARGs, MGEs and 16SrRNA 


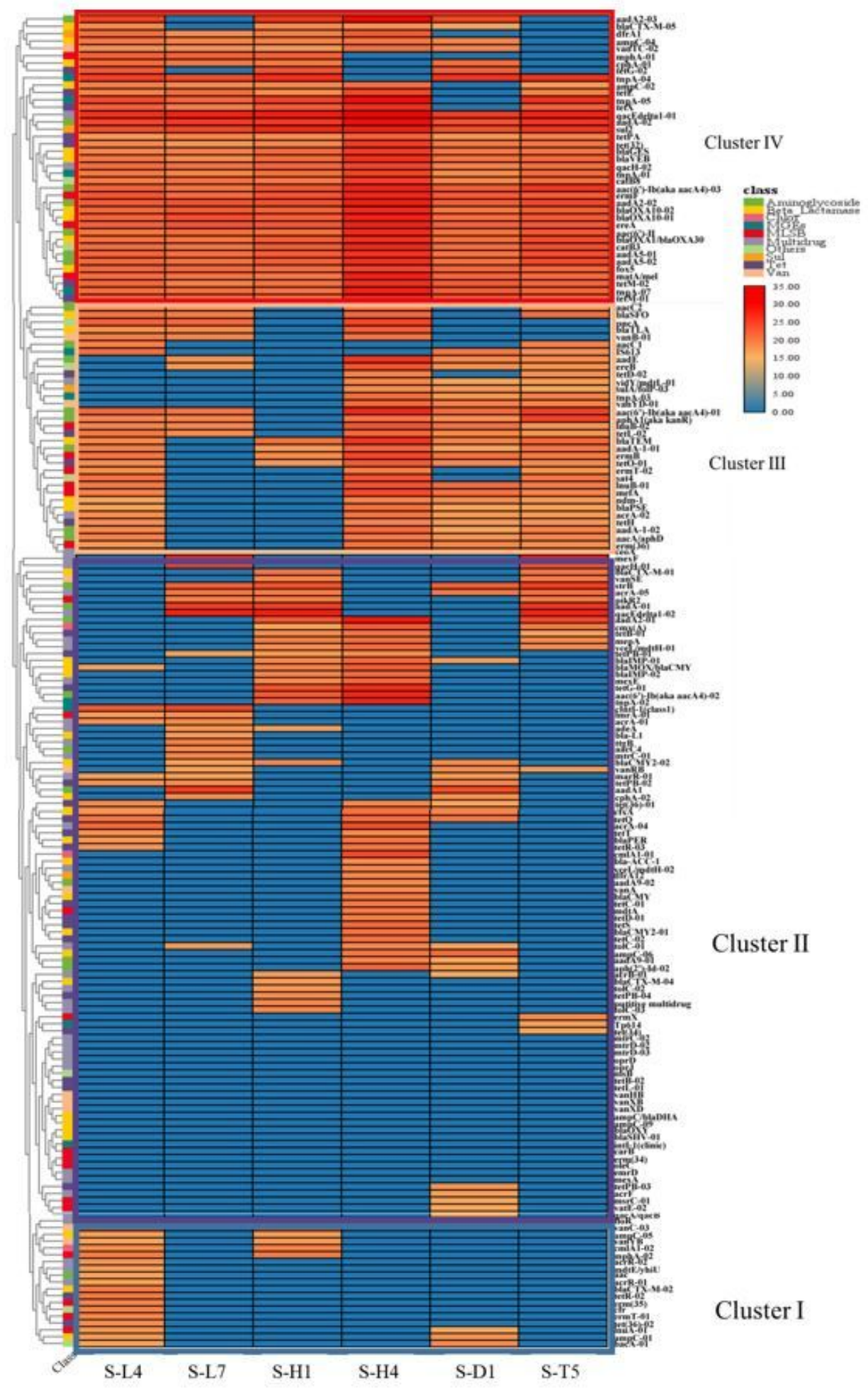

\section{Figure 5}

Detection heat map of the absolute abundances of ARGs and MGEs (using the logarithmic value to base 2). Cluster $\bigotimes$ means that the detection in rural areas is higher than that in cities; Cluster $\bigotimes$ means that both urban and rural detections are low or not detected (only in the reference point); Cluster $\otimes$ means that the detections in cities are higher than rural; Cluster $\otimes$ means that both urban and rural detections are high. 


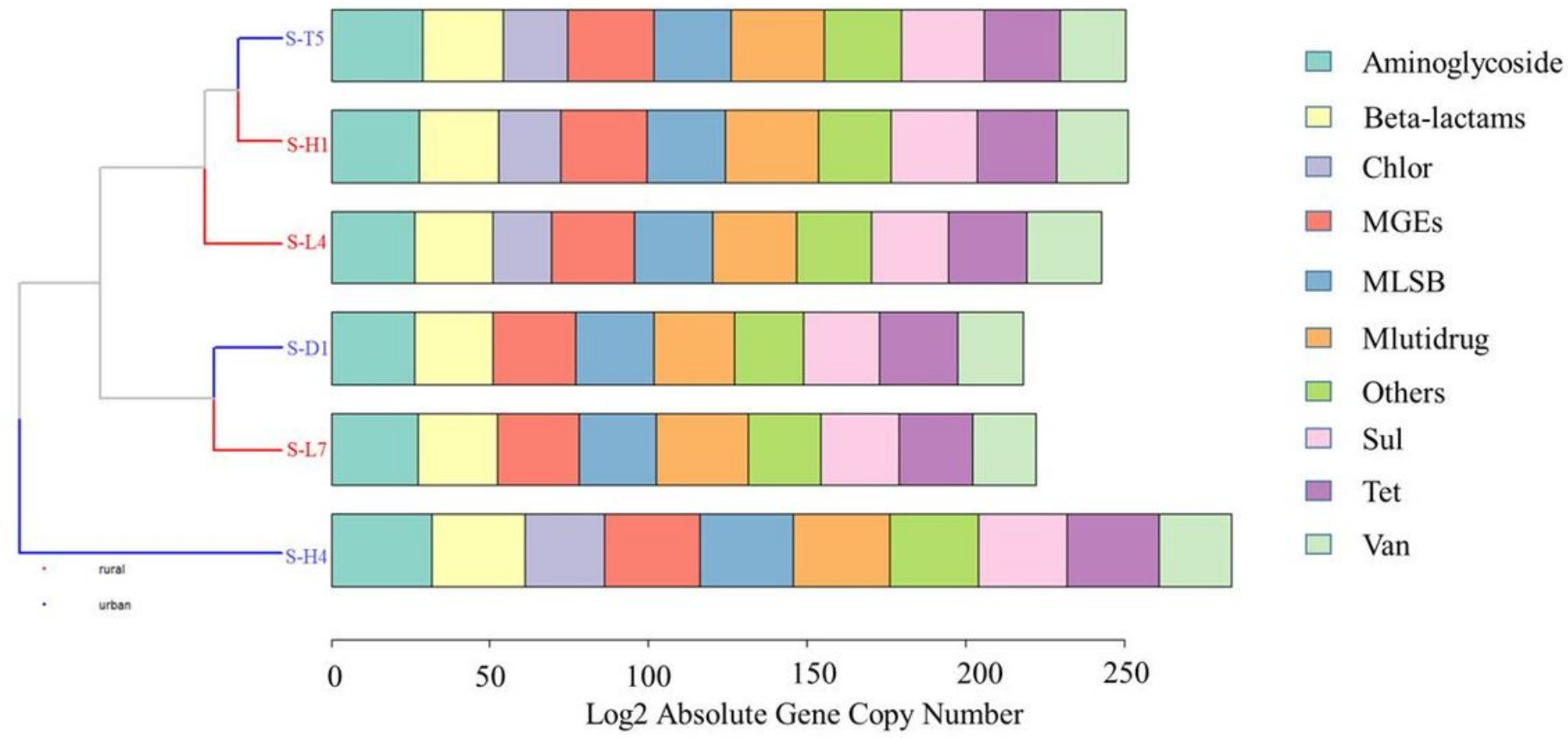

Figure 6

Detected absolute abundances of various types of ARGs and MGEs (using the logarithmic value based on 2)

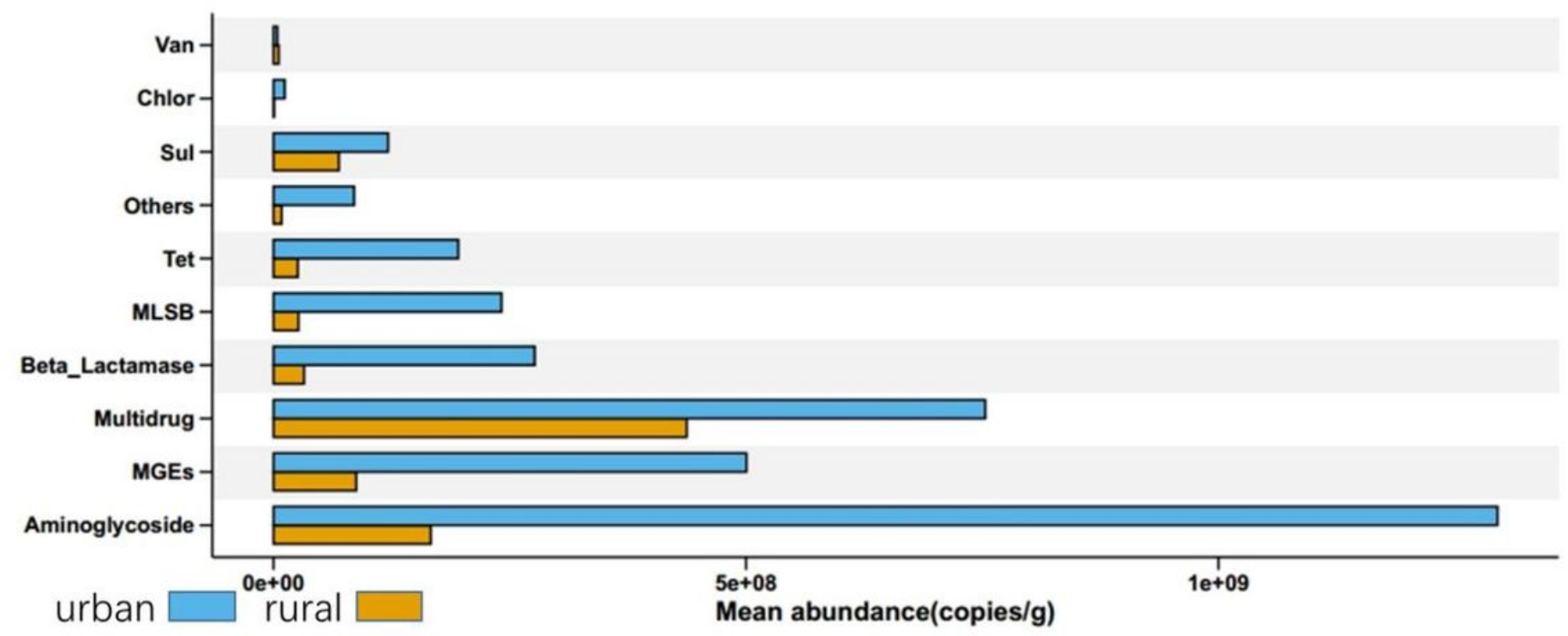

\section{Figure 7}

Comparison of the detection of ARGs and MGEs in urban and rural. $(P=0.039<0.05)$ 


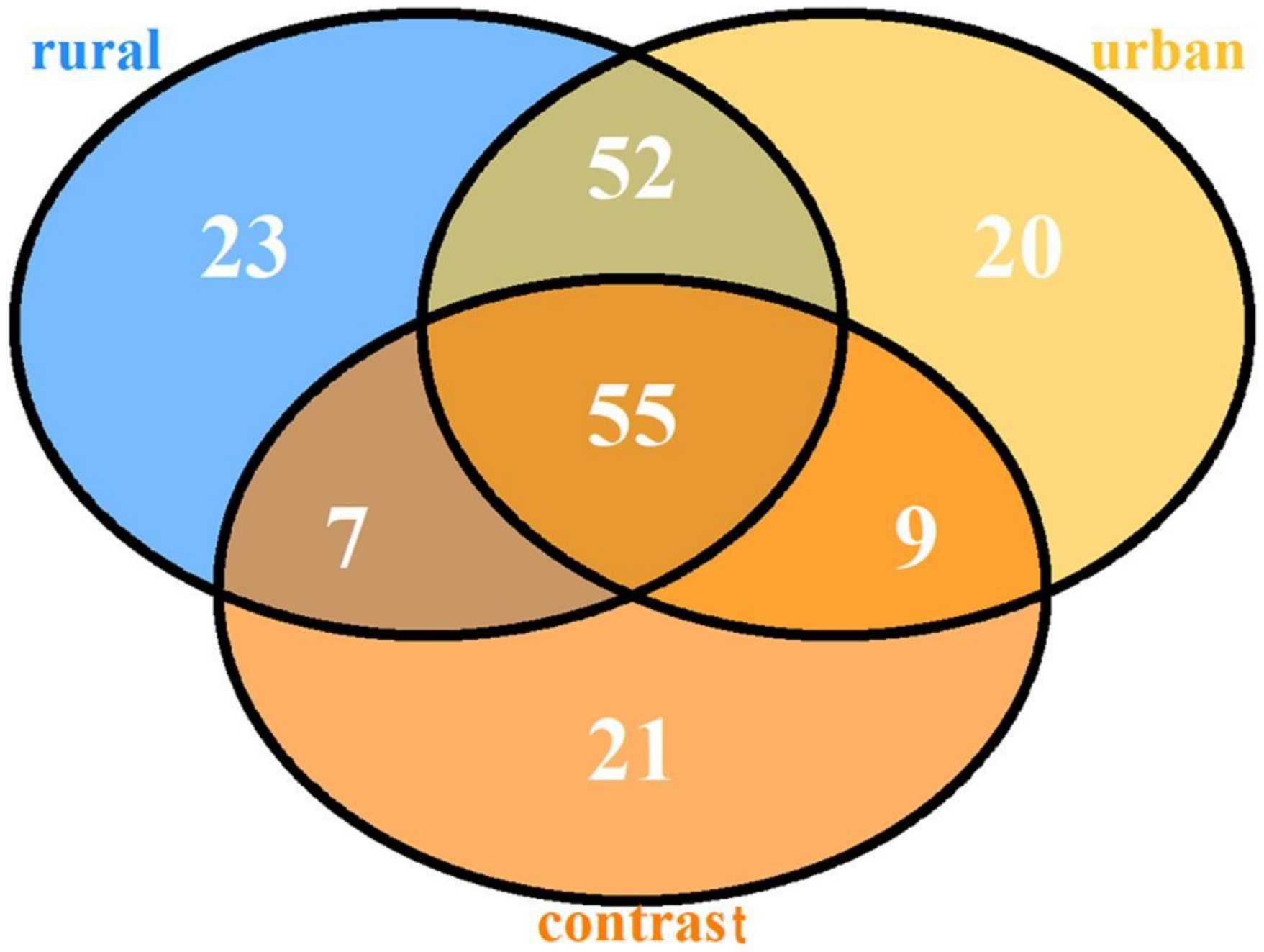

Figure 8

Venn diagram of ARGs and MGEs detected in urban, rural and control 


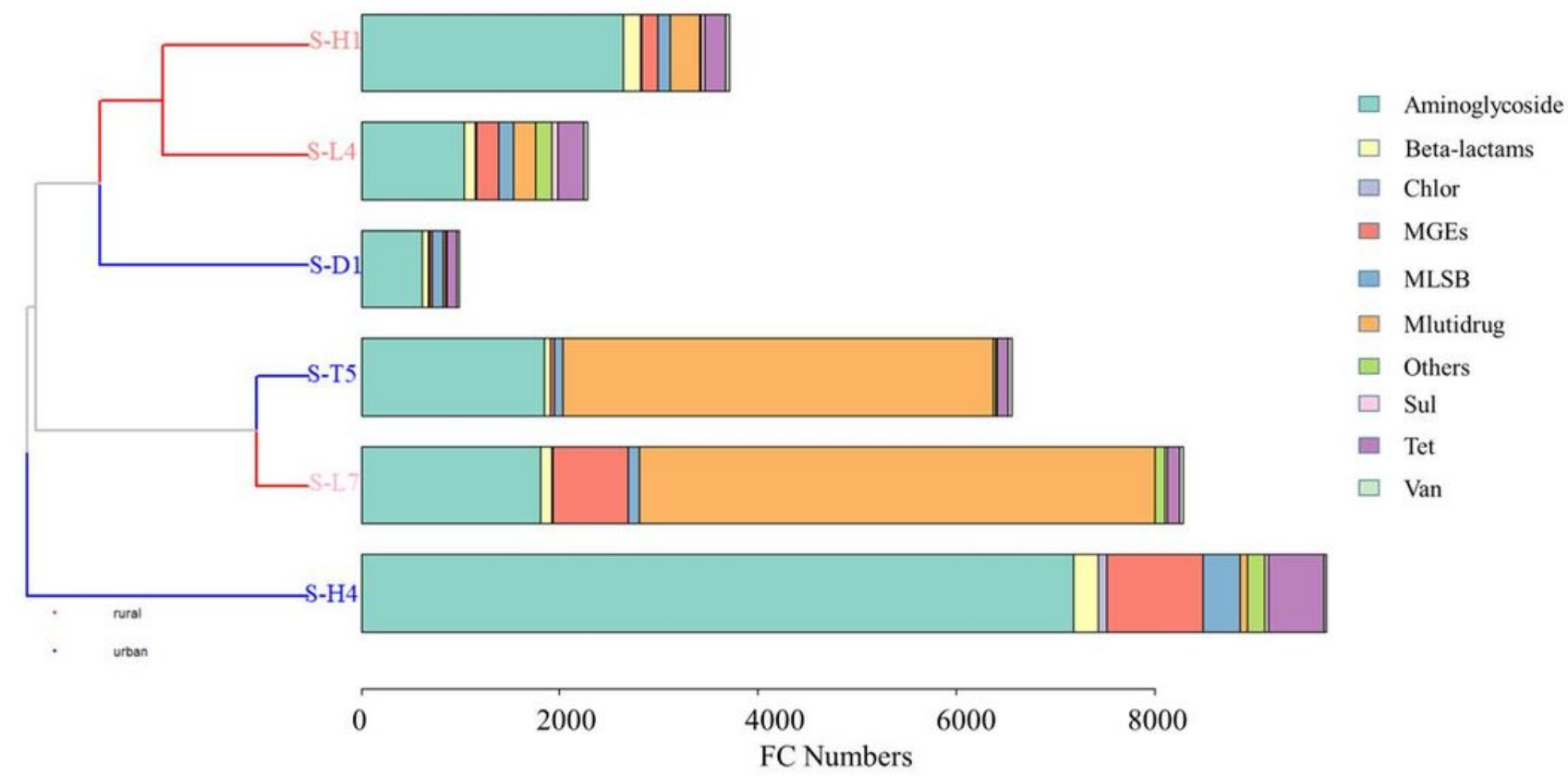

Figure 9

Distribution of FC values detected by ARGs and MGEs 


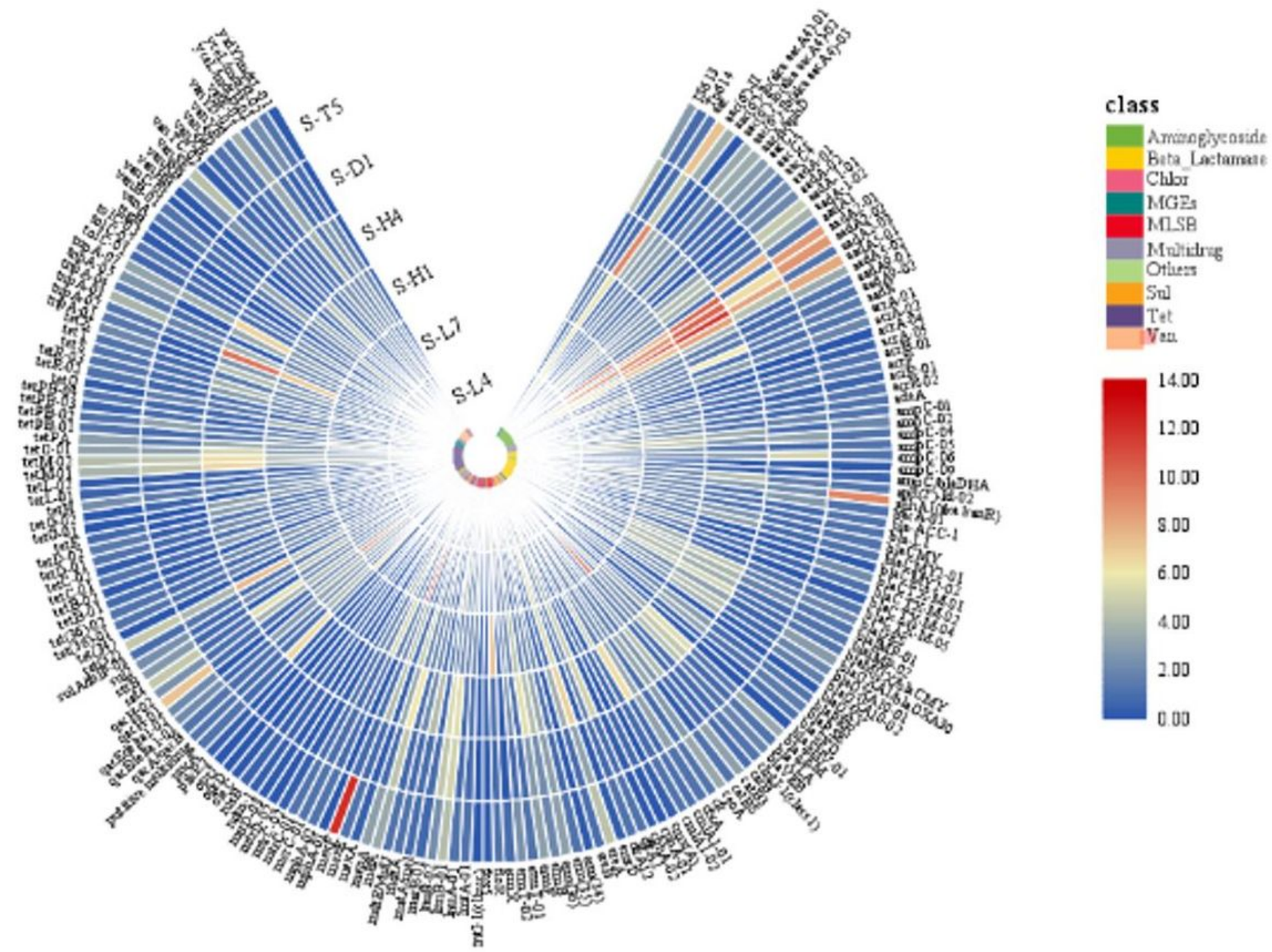

Figure 10

Heat map of FC values detected by ARGs and MGEs (take the logarithmic value based on 2) 


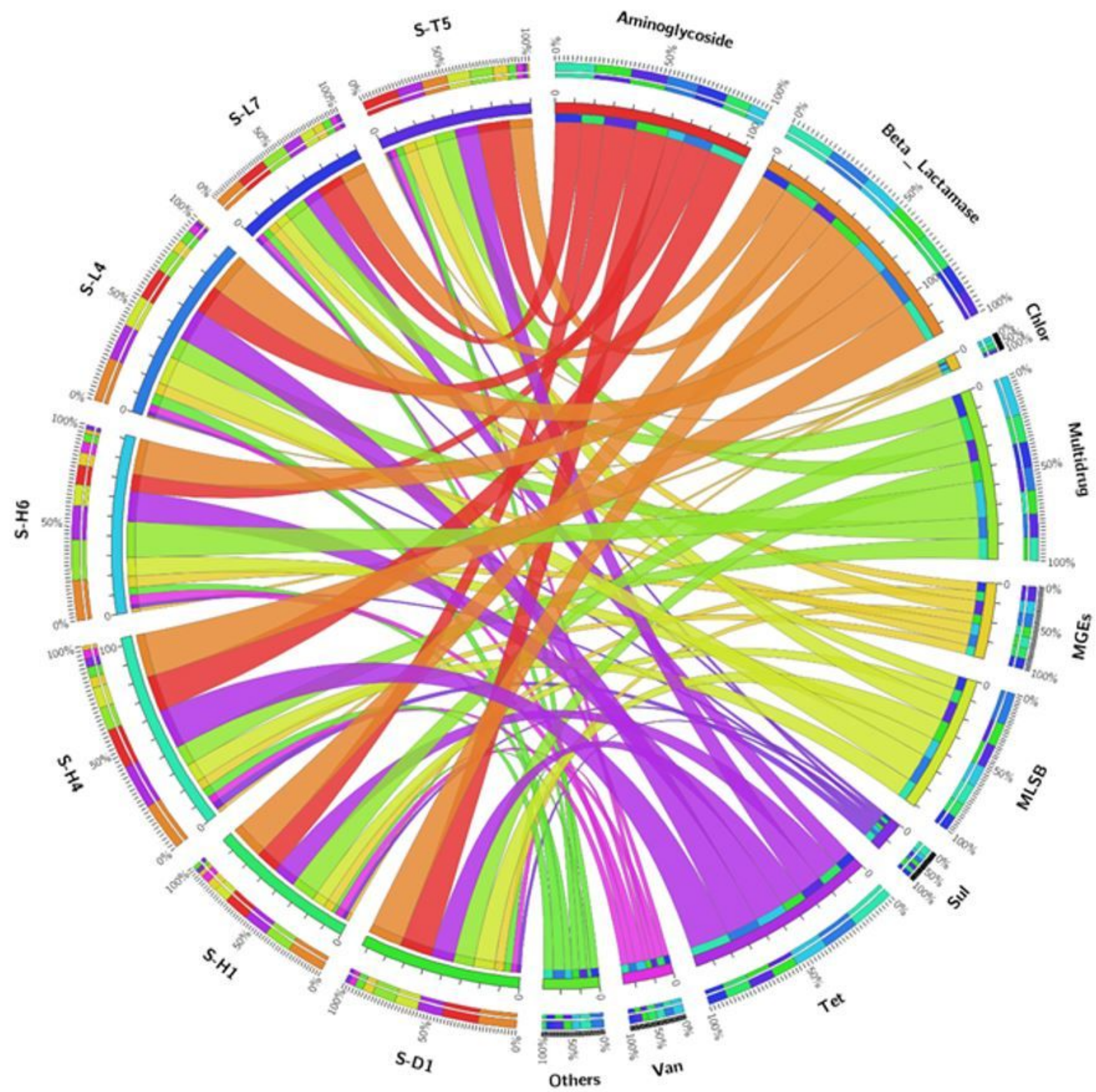

Figure 11

Association diagram of sampling points and resistance genes The left side of the figure represents each sampling point, and the right side represents different types of antibiotic resistance genes; the left and right sides were connected with each other to indicate the degree of association between the corresponding site and the resistance gene. The value is $0 \% \sim 100 \%$, corresponding the higher the value, the higher the concentration of resistance gene at the locus. 




Figure 12

Analysis of the network structure of the co-occurrence of MGEs and ARGs, $|\rho| \geq 0.6, P<0.05$. Each node in the figure represents the detected gene. The larger the point, the more important the co-occurrence position. The color of the point indicates different types of ARGs or MGEs.

\section{Supplementary Files}

This is a list of supplementary files associated with this preprint. Click to download.

- Supplementarymaterial.docx 